\title{
EPISTIMOLOGI ISLAM DALAM PERPSEKTIF M. ABID AL JABIRI
}

\author{
Zaedun $\mathrm{Na}$ 'im \\ STAI Ma'had Aly Al-Hikam Malang \\ Email: zaedunnaim82@gmail.com
}

\begin{abstract}
The development of the science of development is slowly growing rapidly, more so in the western world based on the main base, namely rationalism, and empiricism. However, it is in contrast to the treasures of Islamic scholarship which stagnated due to differences in perceptions of accepting or rejecting science which only stems from rationalism and empiricism. Based on this anxiety, there was an effort made by one of the leading Muslim figures named M. Abid Al Jabiri who tried to construct ideas about the importance of the development of science in Islamic treasures with an Islamic epistemological approach. Therefore, this paper was appointed to reveal more deeply how the views of M. Abid Al Jabiri in the development of Islamic scientific treasures with an Islamic Epistemology approach so that with his view it provides a solution to confusion and adversity in the development of Islamic scholarship. This study method uses a qualitative approach with the type of library research. Through this type of research, the author collects various references regarding the views of M. Abid Al Jabiri on Islamic epistemology which the authors then analyze and can finally produce a conclusion. The results of this study conclude that in M. Abid Al Jabiri's view, Islamic epistemology through Bayani, Irfan, and Burhani epistemologies is an answer to how important it is to use Islamic epistemology for the development of Islamic scholarship so that it does not lag behind the dominance of Western scientific development.
\end{abstract}

Keywords: Islamic epistemology, M. Abid Al Jabiri

Ada sebuah uraian kalimat yang penulis ambil dari tulisan Zulfata, yang menyebutkan bahwa "Khazanah pemikiran Islam dari masa ke masa terus mengalami perubahan sesuai dengan perubahan ruang, dan tempat dan waktu"(Zulfata, 2016). Kalimat ini bisa dipahami bahwa dalam perubahan ruang, tempat dan waktu sangat berpengaruh terhadap perubahan atau perkembangan pemikiran Islam, sehingga sejarah tidak bisa dilupakan karena itu menjadi cerminan dan pegangan dalam melakukan pengembangan atau perubahan dalam pemikiran Islam kedepannya.

Hal ini menunjukkan pemikiran Islam menarik untuk terus dikaji dengan berbagai dinamika perjalanan waktu yang terus berjalan dan tentunya akan menemukan banyak hal dalam memperkaya khazanah keilmuan keislaman, sebagaimana pemikiran Islam yang dikembangkan oleh Muhammad Abid Al Jabiri melalui epistimologinya dan epistemologi merupakan cabang filsafat yang secara khusus membahas teori ilmu pengetahuan. 
Epistemologi berasal dari bahasa Yunani, "episteme" yang berarti pengetahuan. Untuk memperoleh Epistimologi setidaknya ada beberapa pertanyaan yang perlu kita pecahkan, sebagaimana yang diuraikan M. Amin Abdullah bahwa pertama, apakah sumber-sumber pengetahuan itu? kedua, dari manakah pengetahuan yang benar itu datang dan ketiga, bagaimana kita mengetahuinya? (Khairina, 2016).

Sebagaimana pula pendapat M. Amin Abdullah, bahwa "dalam dunia pemikiran, epistemologi menempati posisi penting, sebab ia menentukan corak pemikiran dan pernyataan kebenaran yang dihasilkannya". Ditambahkan beliau bahwa "Bangunan dasar epistemologi berbeda dari satu peradaban ke peradaban yang lain". Titik tekan perbedaan dalam epistemologi memang besar sekali pengaruhnya dalam konstruksi bangunan pemikiran manusia secara utuh. Sehingga melalui epistemologi pandangan dunia manusia akan terpengaruh bahkan dibentuk oleh konsepsinya (Hafizillah \& Wafa, 2019).

Berkenaan dengan pendekatan epistimologi ini, ada salah satu tokoh pemikir Islam kontemporer yang mengkritisi penggunaan epistimologi ini yakni Muhammab Abid al Jabiri, merupakan seorang pemikir kontemporer, filosof, dan sosiolog Arab. Sejak awal Concern pengetahuan al Jabiri memang memfokuskan diri pada kajian kebangkitan kembali rasionalisme Arab, dengan harapan bisa mengejar ketertinggalan dan kemajuan yang dicapai oleh bangsa Eropa pada abad-abad terakhir (Fawaid, 2015).

Kemudian Al Jabiri menawarkan sebuah rekonstruksi epistemology yang dapat untuk membantu mengembangkan ilmu keagamaan yang dirasa berbeda dibanding dengan keilmuan yang berada di dunia Barat,. Secara umum kritik al Jabiri ditujukan kepada nalar Arab-Islam yang pada akhirnya menyatu dalam sebuah "turats" atau "kebudayaan".

Al Jabiri memiliki pandangan bahwa, agar proyek kebangkitan Arab tidak mengalami keterputusan sejarah, kebudayaan seharusnya menjadi titik tolak kritik nalar. Oleh Karena itu persoalan keterpurukan bangsa Arab sejatinya disebabkan karena mereka terjebak dalam memahami dan memperlakukan kebudayaan, yang 
cenderung bergerak ke arah"sirkular" dan bahkan tidak bergerak kearah “pembaharuan". Sehingga dalam hal ini Al Jabiri menawarkan epistemologi pengkajian Islam yang meliputi tiga aspek yaitu, bayani, irfani dan burhani (Pramandira, 2018).

Terkait pemikirian Al Jabiri dengan bangunan epistimologi ini, ada beberapa tulisan yang sudah mencoba menganalasisnya, antara lain tulisan Rosi Manila sebuah karya hasil skripsinya yang di dikutip oleh Zulfata dalam artikelnya yang berjudul "Konsep Epistemologi Muhammad Abed Aljabiri". Dalam tulisan tersebut cenderung membahas dampak-dampak dari konsep epistemologinya semata tanpa ada proses analisis yang lebih kritis terhadap pola pemikiran Muhammad Abed Al Jabiri (Zulfata, 2016). kemudian tulisan yang selanjutnya ditulis oleh Zulfata yang berjudul "Kritik Formasi Nalar Arab". Zulfata mengangkat judul tersebut sebagai bahan memahami pola pemikirannya Muhammad Ābid al-Jābirī serta faktor-faktor yang mempengaruhi atau memicu pemikirannya tersebut. Pada bagian inti hasil analisis Zulfata memberi kesimpulan bahwa "corak pemikiran Ābid al-Jābirī bersifat kritik historis yang terkandung di dalam sistem kebudayaan bangsa Arab" (Zulfata, 2016).

Berbeda dengan apa yang sudah dikaji oleh penulis sebelumnya, penulis kali ini mencoba menggali lebih dalam bagaimana peta atau ruang lingkup dari epistimologi yang dikembangkan oleh Al Jabiri, sehingga penulis mengangkat judul Muhammad Abid Al Jabiri: Peta Epistimologi Islam. Harapan penulis mengangkat tema tersebut agar bisa lebih dalam pemahaman tentang ruang lingkup dari epistimologi Islam yang ditawarkan oleh Al Jabiri.

\section{METODE PENELITIAN}

Dalam telaah ini penulis menggunakan penelitian kualitatif dengan pendekatan studi pustaka atau library research dan bersifat deskriptif, dimana penulis ingin mengungkap lebih dalam tentangan pandangan M. Abid Al jabiri tentang konsep epistimologi Islam. Dalam melalui library research ini penulis mengumpulkan dokumen atau data data terkait pandangan M. Abid Al Jabiri 
tentang epoistimologi Islam yang bersumber dari beberapa referensi, seperti buku, jurnal, dan lainnya. Sehingga dari data data yang dikumpulkan akan direduksi menjadi suatu telaah mendalam dan menghasilkan sebuah kesimpulan tentang Epistimologi Islam dalam perspektif M. Abid Al Jabiri.

\section{HASIL DAN PEMBAHASAN}

\section{Biografi M. Abid Al Jabiri}

Al Jabiri lahir di Figuig, sebelah selatan Maroko, tahun 1936. Pendidikan Al Jabiri lebih banyak ditempuh di tanah kelahirannya, Maroko. Beliau menempuh pendidikan filsafat di Universitas Damaskus selamaa setahun di Syria tahun 1958. kemudian tahun 1967 melanjutkan pendidikan diploma di Sekolah Tinggi Filsafat Fakultas Sastra Universitas Muhammad al Khamis di Rabat dan Tahun 1970 meraih gelar master Doktor bidang Filsafat, beliau raih di kampus yang sama sebelumnya (Fawaid, 2015).

Nama Muhammad Abid Al Jabiri dalam kancah intelektual muslim kontemporer bukanlah nama yang asing atau sudah masyhur. Dia dikenal dengan proyek Naqd al-'Aql al-'Arabīnya (Kritik Nalar Arab) yang monomental. Sejak awal 1970-an tidak kurang dari 20 tahun al-Jabiri membangun tradisi kritik terhadap pemikiran Islam melalui menulis sejumlah buku(Rozi, 2018).

Sebagai pemikir Islam kontemporer pada posisi garda terdepan, al-Jabiri sudah tentu didukung oleh latar belakang lingkungan intelektual, budaya, dan situasi sosial-politik di sekitarnya. Maroko merupakan negeri yang pernah menjadi wilayah protektoriat Perancis. Setelah merdeka, negeri Maroko mengenal dua bahasa resmi, Arab dan Perancis. Menurut suatu tesis kaum post-strukturalis bahwa" bahasa menentukan ukuran, bentuk dan kandungan pemikiran seseorang atau kelompok", maka tradisi bahasa Prancisme memudahkan para sarjana Maroko mengenal warisan pemikiran yang menggunakan bahasa Prancis (Rozi, 2018) 


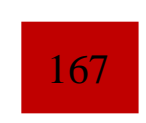

Dengan melihat historis dari Al Jabiri terkait letak geografis dan interaksinya dalam dunia pemikiran Islam menunjukkan pengaruh situasi dan tempat sangat berpengaruh terhadap terbentuknya pemikiran al Jabiri dan pengembangan keilmuan keislaman yang ditekuninya.

2. Pemikiran Muhammad Abid Al Jabiri

Menurut Bakker $d k k$. yang dikutip oleh Ahmad Fawaid menyatakan, bahwa kita tidak bisa mengabaikan perspektif sosial historis-politis ruang lingkup yang memengaruhinya dalam memahami pemikiran seseorang. Oleh karenanya ada berbagai faktor yang turut terlibat dalam menemukan karakteristik pemikiran seseorang. Sebab pemikiran adalah sebuah anak zaman yang menyertai pengalaman seseorang. Masing-masing orang bergumul antar relasi dengan dunianya, untuk membentuk nasibnya dan sekaligus dibentuk olehnya (Fawaid, 2015).

Melalui perkenalannya dengan pemikir-pemikir Perancis pada tahun 1950an terbentuklah pemikiran al Jabiri. Diawali saat beliau masih kuliah di Universitas Muhammad al Khamis, Rabat, Maroko. Al Jabiri menyatakan dalam bukunya yang berjudul, al Turats wa al Hadatsah, dirasat wa munaqasat, bahwa pemikiran-pemikiran Marxisme sedang berkembang subur di kawasan Arab. Dan Al Jabiri mampu menguasai literatur perancis yang membahas tentang Marx, termasuk buku Marx sendiri. Namun al Jabiri meninggalkan berbagai kritik atas pendekatan metodologis Marx, kendatipun dipengaruhi oleh pemikiran Marx (Fawaid, 2015).

Terkait pendekatan metodologis Marx, mendorong al-Jabiri mempertanyakan tentang asumsi-asumsi kaum orientalis yang terkesan hanya memaksakan kepentingan mereka dalam mengkaji Islam. Dan hal ini menjadikan al-Jabiri menitikberatkan kritiknya pada aspek metodologi dan kerangka berpikir kaum orientalis, dan bukan pada detail-detail dan konklusi mereka (Rozi, 2018). 
Al Jabiri menawarkan tiga pendekatan dalam proses objektifikasi, yakni (Fawaid, 2015):

a. Historisitas (tarikhiyyah),

b. Objektifitas (maudluiyyah),

c. Kontinuitas (istimrariyyah)

Al Jabiri berpendapat bahwa, "pendekatan pertama dan kedua sama-sama bertujuan untuk pemisahan antara pembaca dan objek", sementara "pendekatan ketiga bertujuan untuk menghubungkan pembaca dengan objek bacaannya”. Beliau tambahkan bahwa, bentuk pemisahan dalam bentuk pertama dan kedua bertujuan menempatkan tradisi sebagai objek kajian kritis. Menurut beliau, ini penting dilakukan sebab seseorang terkadang menyelinapkan subjektifitasnya demi kepentingan tertentu ketika membaca tradisi.

Al Jabiri menggagap bahwa "titik kunci" melalui Epistimologi nalar Arab lah untuk bisa memasuki semesta peradaban Arab yang membentuk secara keseluruhan bangunan keislaman yang berkembang, bukan hanya di wilayah Arab, namun seluruh dunia, Dari asumsi epitimologis ini, beliau melakukan analisis-analisis historis, yang memungkinkan terbentuknya nalar bayani, 'irfani dan burhani beserta seluruh rangkain yang terjalin di dalamnya (Khairina, 2016).

Ini menunjukkan pemikiran al Jabiri sangat kritis dan concern terhadap peradaban Arab melalui studi kritisnya dengan bangunan epistimologi Islam, yakni bayani, irfani dan burhani sehingga hal ini menunjukkan peradaban Arab menjadi sesuatu yang menarik untuk terus dikaji dan diungkap lebih dalam agar menambah khazanah pengetahuan bagi umat Islam dan umat manusia.

3. Epistimologi Islam menurut Muhammad Abid al Jabiri

Secara etimologis, epistimologi berasal dari bahasa Yunani, episteme yang berarti pengetahuan dan logos yang berarti perkataan, pikiran, dan ilmu. Secara harfiah, epistimologi berarti " studi atau teori tentang ilmu pengetahuan ( the study of or theory of knowledge). Namun dalam kiskursus filsafat, epistimologi merupakan cabang dari filsafat yang membahas tentang asal usul, struktur, metode, dan kebenaran pengetahuan (Susanto, 2015). 
Dengan demikian, epistimologi pada dasarnya merupakan suatu upaya rasional untuk menimbang dan menentukan nilai kognitif pengalaman manusia dalam interaksi diri, lingkungan sosial, dan alam sekitarnya. Maka epistimologi adalah suatu disiplin ilmu yang bersifat evaluatif, normatif, dan kritis (Susanto, 2015).

Berbicara tentang epistimologi, Plato (427-347 SM) dapat dipandang sebagai peletak dasar idealism yang kemudian lebih popular disebut dengan rasionalisme. Epistimologi pada masa Plato bersifat rasional spekulatif, artinya pemikiran rasional Plato semata-mata didasarkan pada keyakinan akan adanya dunia ide, yaitu ide-ide bawaan manusia, tidak benar-benar didasarkan pada pemikiran yang bertitik tumpu pada fakta-fakta empiris (Susanto, 2015).

Perjalanan epistimologi pada masa Aristoteles mengalami perubahan jika dibandingkan pada masa Plato, karena Aristoteles telah mendasarkan pada pengamatan inderawi, sedangkan plato mendasar pada dunia ide. Akan tetapi, epistimologi yang hanya didasarkan pada dunia ide dan pengamatan inderawi mengalami keterbatasan. Dan untuk mengatasi keterbatasan epistimologi dualistk tersebut, diperlukan perangkat ketiga, yaitu suatu perangkat yang dapat mengakomodasi unsur rasa, yaitu intuisi. Melalui intuisi dapat diperoleh pengetahuan yang relatif berbeda dari pengetahuan yang dihasilkan oleh perangkat rasio dan indra. Bahkan, para intuisionis mengklaim bahwa pengetahuan hakiki itu hanyalah pengetahuan yang diperoleh dengan melibatkan intuisi (Susanto, 2015).

Epistimologi ala Platonian dan Aristotelian tersebut kemudian dipahami dan diambil oleh para filsuf Muslim, seperti al-Kindi (w.873), al-farabi (870-950), dan Ibn Sina (980-1037) dan lainnya. Karena hidupanya selalu dijiwai oleh wahyu, para filsuf Muslim tersebut menambahkan bahwa pengetahuan dapat diperoleh melalui wahyu Dan perlu digarisbawahi bahwa epistimologi yang semula berkembang di Yunani yang bersifat rasional spekulatif itu, kemudian dikembangkan oleh para filsuf Muslim, seperti al Farabi dan Ibn Sina menjadi rasional empirik, yang untuk selanjutnya dikembangkan Al Ghazali menjadi 
empirik transendental, dan akhirnya sampai pada Ibn Rusyd menjadi empirik eskperimental(Susanto, 2015).

Berkenaan dengan epistimologi diatas, Al Jabiri melakukan kritik epistemologis terhadap bangunan tradisi keilmuan Arab Islam sebagai proyek pembaharuan. Tugas utamanya adalah mengkaji ulang sejarah budaya Arab-Islam dan sekaligus menganalisis nalar Arab. Hal ini mendorong al-Jabiri untuk menganalisis background Sosiopolitik proses perumusan dan keterbentukan nalar Arab-Islam, dan Sekaligus menganalisis secara mendalam seluk beluk mekanisme kinerja struktur nalar-nalar Arab yang tidak jarang saling berbenturan.

Secara operasional, Kritik Nalar Arab yang dilakukan al Jabiri adalah menganilisis proses-proses kinerja "al- 'aql al-mukawwin” dalam membentuk "al'aql al-mukawwan" pada babakan sejarah tertentu dan mencari kemungkinankemungkinan "al-'aql al-mukawwin" membentuk teori-teori baru. Dengan melakukan kritik terhadap Nalar Arab maka berarti membongkar dan menggali lapisan terdalam rancang bangun pemikiran Arab untuk menguak "cacat-cacat epistemologis" kemudian membenahinya, atau bahkan mencari alternatifnya (Faisol, 2010).

Menurut al Jabiri dalam bukunya "Takwin al-aql al-Araby", yang berisi bahwa bayani, irfani dan burhani adalah epistimologi dalam rangka mencari suatu kebenaran dan kejelasan. Ditambahkan beliau bahwa Bayani yang bersumber pada teks (wahyu), epistimologi irfani yang bersumber pada pengalaman atau experience, dan epistimologi burhani yang bersumber pada akal dan rasio (Khairina, 2016).

Untuk lebih jelasnya dalam memahami ketiga epistemologi tersebut, yakni epistemologi bayani, Irfani, dan Burhani dalam pandangan Muhammad Abid al Jabiri akan diuraikan sebagaimana berikut:

1) Epistimologi Keilmuan islam; Bayani

Secara leksikal, term bayani mengandung lima arti, yaitu: (1) al waslu (sampai, berkesinambungan); (2) al-fasl (terputus, keterpilahan); (3) al-zuhur wa al-wuduh (jelas dan terang); (4) al fasahah wa al-qudrah 'ala al-Tabligh wa al- 
'iqna (sehat dan mampu menyampaikan dan menenangkan); dan (5) al-insan hayawan al-mubin (manusia hewan berlogika)(Susanto, 2015)

Bayani adalah suatu epistimologi yang mencakup disiplin ilmu yang berpangkal dari bahasa arab (yaitu nahwu, fiqh, dan ushul fikih, ilmu kalam dan balaghah). Masing-masing disiplin ilmu ini terbentuk dari satu sistem kesatuan bahasa yang mengikat basis-basis penalarannya (Susanto, 2015).

Epistimologi ini dapat dipahami dari tiga aspek, yaitu aspek aktivitas pengetahuan, diskursus pengetahuan dan aspek sistem pengetahuan. Sebagai aktivitas pengetahuan, bayani berarti "tampak menampakkan" dan "paham memahamkan'. Sebagai diskursus pengetahuan, bayani berarti dunia pengetahuan yang dibentuk oleh ilmu Arab Islam murni, yaitu ilmu bahasa dan ilmu agama. Sementara itu, sebagai sistem pengetahuan, bayani berarti "kumpulan dari prinsipprinsip, konsep-konsep dan usaha-usaha yang menyebabkan dunia pengetahuan terbentuk tanpa disadari” (Susanto, 2015).

Secara sederhana menurut Abid Al-jabiri, nalar bayani terdapat dalam kajian ilmu kebahasaan, nahwu, fiqih (yurisprudensi Islam), teologi (ilmu kalam) dan ilmu balaghah. Nalar bayani bekerja dengan menggunakan mekanisme yang sama berangkat dari dikotomi antara lafadzl al-makna, al-ashl/al-far' dan aljauharlal-ardl (Faisol, 2010).

Dalam epistimologi bayani ini al Jabir lebih menitikberatkan pada aspek pemahaman yang luas terhadap dalam memahami suatu teks melalui menggali lebih dalam aspek kebahasaan dan menempatkan kebenaran wahyu (teks) pada prioritas utama dibandingkan dengan kebenaran yang dihasilkan melalui penggunaan akal.

2) Epistemologi Keilmuan Islam: Irfani

Kata irfan (gnosis) merupakan bentuk masdar dari kata 'arafa yang artinya “pengetahuan”, ilm dan hikmah (Susanto, 2015). Dan Irfani (gnostik), kata ini semakna dengan makrifat, berarti pengetahuan yang diperoleh secara langsung lewat pengalaman, sedangkan ilmu adalah pengetahuan yang didapat lewat transformasi ( $n a q l)$ dan rasionalitas $(a q l)$. Sistem epistemologi irfani didasarkan atas adanya perbedaan antara yang batin atau manifest dan yang zahir atau laten. 
Hal yang bersifat batin memiliki posisi tertinggi dalam herarki pengetahuan irfani(Hafizillah \& Wafa, 2019).

Jika sumber pokok ilmu pengetahuan dalam tradisi bayani adalah teks (wahyu), maka sumber terpokok ilmu pengetauhuan dalam tradisi berfiki 'Irfānī adalah "experience" (pengalaman). Dan Validitas kebenaran epistemologi irfani hanya dapat dirasakan dan dihayati secara langsung (arru'yah al-mubāshirah), intuisi, az-zauq atau psiko-gnosis (Rozi, 2018).

Nalar 'Irfānī berusaha menyesuaikan konsep yang diperoleh melalui kasyf dengan teks. Dengan kata lain, seperti yang dikatakan oleh al-Ghazali, zahir teks dijadikan cabang, sedangkan konsep atau pengetahuan kasyf sebagai pokok Karena itu, model 'Irfān̄̄ ini tidak memerlukan persyaratan 'illat sebagaimana dalam bayān̄i, tetapi hanya bepedoman pada isyarat (petunjuk batin) (Rozi, 2018). Dan menurut Al-Jabiri, pengalaman kasyf dihasilkan melalui mujahadah dan riyadah (penempaan diri secara moral spritual) tidak dihasilkan melalui proses penalaran intelektual manusia yang mana manusia dituntut aktif dan kritis, tetapi dihasilkan melalui mujahadah dan riyadah (penempaan diri secara moral spritual) (Kusuma, 2018).

Dalam konteks dialetik agama dan plularitas seni tradisi budaya lokal, pendekatan irfani ini memiliki dua tugas penting yaitu (Hafizillah \& Wafa, 2019):

a) Membaca makna-makna terdalam dari simbol-simbol dan isyarat-isyarat teks keagamaan.

b) Membaca makna-makna terdalam dari simbol-simbol dan isyarat-isyarat yang terkandung dalam bentuk seni tradisi atau budaya.

Al Jabiri menyoroti penggunaan epistimologi irfani yang tidak mudah digunakan oleh semua orang namun hanya orang-orang tertentu sehingga dalam menyikapi permasalahan agar mencapai kebenaran secara cepat untuk dihindari pemakaian metode ini, dan bisa menggunakan alternatif lain yang lebih cepat dan tepat sehinga permasalahan yang dihadapi umat cepat terselesaikan.

3) Epistimologi Keilmuan Islam:Burhani

Al Burhan berarti argument yang pasti, tegas, dan jelas. Dalam pengertian yang sempit, burhani adalah aktivitas pikir untuk menetapkan kebenaran 
pernyataan melalui metode penalaran, yakni dengan mengikatkan pada ikatan yang kuat dan pasti dengan pernyataan yang aksiomatis. Dalam pengertian yang luas, burhani adalah setiap aktivitas pikir untuk menetapkan kebenaran pernyataan (Susanto, 2015).

Secara fundamental, setidaknya terdapat tiga prinsip yang melandasi konstruksi epistemologi burhani, yaitu:

a) Rasionalisme (al-'aqlaniyah),

b) Kausalitas (al-sababiyah),

c) Esensialisme (al-Mahiyyah),

Ketiga hal diatas dikembangkan melalui penggunaan metode utama: deduksi dan induksi. Mengingat pengetahuan adakalanya diperoleh melalui indra dan adakalanya melalui rasio. Hal ini secara jelas berbeda jika dibandingkan dengan sistem epistemik bayani dan irfani yang secara apriori telah menjadikan realitas kewahyuan (al-Qur'an dan Hadis) yang dikemas dalam wacana bahasa dan agama sebagai acuan berpijak bagi pemerolehan pengetahuan (Susanto, 2015)

al-Jabiri menegaskan bahwa burhani menghasilkan pengetahuan melalui prinsip-prinsip logika atas pengetahuan sebelumnya yang telah diyakini kebenarannya. Di samping itu, dalil-dalil logika tersebut memberikan penilaian dan keputusan terhadap informasi yang masuk lewat indera, yang dikenal dengan istilah tasawwur dan tasdiq. Tasawwur merupakan "proses pembentukan konsep berdasarkan data-data dari indera", sedangkan tasdiq merupakan "proses pembuktian terhadap kebenaran atau konsep tersebut" (Damanik, 2019).

Jika sumber ilmu dari corak epistemologi Bayān̄̄ adalah teks, sedang 'Irfān $\bar{\imath}$ adalah pengalaman langsung, maka epistemologi Burhān̄ merupakan episteme yang bersumber pada realitas atau al-wāqi' baik realitas alam, sosial, humanitas maupun keagamaan. Peran akal pikiran sangat menentukan disini, karena fungsinya selalu diarahkan untuk mencari sebab akibat (idräk as-sabab wa al-musabab) (Rozi, 2018). 
Bagi al-Jabiri, Metode burhani bertumpuh sepenuhnya pada seperangkat kemampuan intelektual manusia, baik melalui panca indera, pengalaman, maupun daya rasional, dalam upaya memperoleh pengetahuan tentang semesta, bahkan juga sampai menghasilkan kebenaran yang bersifat pospulatif (Kusuma, 2018).

Selanjutnya, untuk mendapatkan sebuah pengetahuan, epistemologi burhani menggunakan silogisme. Dalam bahasa Arab, silogisme diterjemahkan dengan qiyas atau al-Qiyas al-Jami' yang mengacu kepada makna asal. Secara istilah, silogisme adalah suatu bentuk argumen dimana dua proposisi yang disebut premis, dirujukan bersama sedemikian rupa. Sehingga sebuah keputusan pasti menyertai.

Epistimologi Burhani merupakan metode yang mengandalkan akal atau rasio untuk mengoptimalkaa daya pikir yang sudah dianugerahkan oleh Tuhan kepada manusia sehingga dalam mengggapai kebenaran untuk senantiasa menggali kebenarana bisa memanfaatkan akal untuk memecahkan dan menemukan jawaban atas kebenaran tersebut.

Al-Jabiri menjelaskan bahwa dari ketiga epistemologi tersebut posisi epistemologi burhani ditempat pada posisi paling utama atau paling tinggi setelah itu diikuti oleh epistemologi bayani, karena menurut al-Jabiri metode burhani (baca:akal) akan menguatkan metode bayani (baca: teks). Sementara itu epistimologi irfani-lah yang menyebabkan perkembangan keilmuan Islam terhambat atau menjadi stagnan, karena metode ini merasa semua perkembangan dan proses pencapaian pengetahuan berdasarkan pemberian Tuhan secara langsung atau melalui illuminatif (cahaya), yang kemudian akan berimplikasi atau paling tidak akan melahirkan berbagai konflik-konflik baru (Kusuma, 2018)

Hal ini menunjukkan epistimologi burhani menempati posisi yang tinggi, sehingga dengan memaksimalkan potensi akal akan mendorong perkembangan keilmuan Islam ke seluruh belahan dunia. Karena dengan akal menjadikan manusia akan terus berpikir dengan daya upaya yang kuat untuk terus mengembangkan khazanah keilmuan yang perlu digali lebih dalam. 


\section{PENUTUP}

Sebagai seorang tokoh pemikir islam kontemporer Muhammad Abid al Jabiri sangat concern dan peduli akan khazanah keilmuan islam sehingga beliau sangat getol dalam mengagali informasi yang mendalam yang berkenaan dengan peradaban Islam yang direpresentasikan di dataran Arab. Dan melalui epistimologi bayani, irfani, dan burhani beliau mencoba menggugah umat Islam akan pentingnya penggunaan epistimologi ini untuk pengembangan keilmuan Islam yang sejatinya sudah dipergunakan oleh tokoh-tokoh muslim terdahulu, sehingga hal ini menjadi solusi akan ketertinggalan kemajuan keilmuan dari orang orang Barat 


\section{DAFTAR PUSTAKA}

Damanik, N. (2019). Muhammad Abid Al-Jabiri. Al-Hikmah Jurnal Theosofi Dan Peradaban Islam, 1(2), 116-145.

Faisol, M. (2010). Struktur Nalar Arab-Islam Menurut Abid al-Jabiri. Tsaqafah, 6(2), 335-359.

Fawaid, A. (2015). KRITIK ATAS KRITIK EPISTEMOLOGI TAFSIR M. ABIED AL JABIRI: Studi Kritis Atas Madkhal ila al Quran al Karim. Ulul Albab, 16(2), 157-175.

Hafizillah, Y., \& Wafa, M. A. (2019). Pemikiran Muhammad Abed Al-Jabiri terhadap Nalar Arab: Konsep dan Relevansi. Mawa'izh:Jurnal Dakwah Dan Pengembangan Sosial Kemanusiaan, 10(1), 60-76.

Khairina, A. I. (2016). KRITIK EPISTIMOLOGI NALAR ARAB MUHAMMAD ABED AL-JABIRI. El-Wasathiya: Jurnal Studi Agama, 4(1), 105-116.

Kusuma, W. H. (2018). Epistemologi Bayani, Irfani dan Burhani Al-Jabiri dan Relevansinya Bagi Studi Agama Untuk Resolusi Konflik dan Peacebuilding. Syi'ar, 18(1), 1-19.

Pramandira, A. (2018). Membedah Pemikiran Muhamad Abed Al Jabiri. Nu Online. https://www.nu.or.id/post/read/90618/membedah-pemikiranmuhamad-abed-al-jabiri

Rozi, A. B. (2018). MENIMBANG GAGASAN EPISTEMOLOGI ISLAM ALJABIRI SEBAGAI SOLUSI KEBANGKITAN ISLAM MODERN. Empirisma, 27(2), 73-86.

Susanto, E. (2015). Dimensi Studi Islam Kontemporer (1st ed.). Prenadamedia Group.

Zulfata. (2016). AL-JĀBIRĪ, GAGASAN FORMASI NALAR ARAB ĀBID ACEH, DAN SIGNIFIKANSINYA UNTUK REKONSTRUKSI NALAR. ISLAM FUTURA, 15(2), 320-331. 